\title{
Sexual boundary violations: victims, perpetrators and risk reduction
}

\author{
John Hook \& Dawn Devereux
}

\begin{abstract}
John Hook is a consultant medical psychotherapist in private practice in the UK, having formerly worked as head of psychological therapies services in Southampton and Guildford. $\mathrm{He}$ is a member of the Institute of Group Analysis. His clinical interests include personality disorders and medically unexplained symptoms. He is an associate of the Clinic for Boundaries Studies in London, working with professionals who have a history of misconduct, in particular sexual boundary violations Dawn Devereux is a psychoanalytic psychotherapist in private practice in the UK. She completed a PhD on the patient's experience of psychotherapy. From 2010 to 2016, she was Director of Public Support at the Clinic for Boundaries Studies, where she established and ran a psychotherapy and advocacy service for people who felt harmed through boundary breaches by psychological, medical and complementary practitioners.

Correspondence John Hook, 5 Kemishford, Woking GU22 ORL, UK. Email: hook458@btinternet.com
\end{abstract}

\section{Copyright and usage}

(C) The Royal College of Psychiatrists 2018

\section{SUMMARY}

Sexual boundary violations by healthcare professionals is a subject that has largely been ignored in the UK. There has been little research into the field. It is rarely taught on professional training courses and practitioners appear to know very little about it. The history of sexual boundary violations is littered with failures to notice, failures to report and inadequate justice for victims and perpetrators alike. Perpetrators are commonly assumed to be predators. Given the many widely reported recent events in our media of both predatory and other sexual offenders, we believe it is timely for all healthcare and other professions working with vulnerable people to take the problem seriously, to provide appropriate services for victims, evaluation and assessment of perpetrators, and sanctions that fit the crime in order to regain public trust.

\section{LEARNING OBJECTIVES}

- Develop greater understanding of the problem of sexual boundary violations by professionals

- Be able to manage the care of a patient who has been the victim of a sexual boundary violation

- Understand factors in professionals that may lead to a sexual boundary violation

\section{DECLARATION OF INTEREST}

None.

\section{Keywords}

Sexual boundary violations; perpetrator typologies; assessment of perpetrators; assessment of victims; remediability of perpetrators; types of harm; psychological treatments; psychotherapy.

This is the second of two articles in BJPsych Advances considering harm arising from boundary violations in psychotherapy in particular and healthcare in general. The first (Hook 2018) discussed the general problem of harm in the therapeutic context and explored the adverse idealising transference. In this article we consider sexual boundary violation, its categories, the harm that ensues, the typologies of perpetrators, sanction and remediation, and finally suggestions for improving knowledge in the professions and safeguarding patients.
At the outset it is important to acknowledge that the literature on sexual boundary violations comes mostly from the USA (e.g. Schoener 1989; Pope 1994; Gabbard 2002, 2016; Celenza 2007) and mainly concerns psychotherapy and psychology practice. There has been insufficient research, especially outside the USA, into the different factors and the field is beset by ignorance and defensive attitudes at individual, organisational and societal levels. Some of the research is now more than 25 years old. This emphasises that the findings need to be treated with caution. Our intention is not to judge, but to stimulate openness, discussion and further research.

\section{Categories of sexual boundary violation}

A sexual boundary violation occurs when a professional exploits any aspect of a person's sexuality for personal gain. The Council for Healthcare Regulatory Excellence (2008: p. 5) define sexualised behaviour as 'acts, words or behaviours designed or intended to arouse or gratify sexual impulses or desires'. However, clinical experience suggests that the motivation is rarely the sex itself and involves complex, contradictory psychological needs, including fantasised attempts to heal unresolved conflicts and expression of self-destructive impulses. Misuse of power is a common factor. All professional relationships involve a power imbalance.

In the past, regulators tended to view sexual boundary violations as 'serious' instances if they involved contact with sexual organs and 'less serious' instances if they involved sexualised actions. We suggest that such a divide is unhelpful in assessing both the actions of the professional and the harm to the patient, since any sexualised behaviour is an exploitation of a vulnerable person and can lead to significant harm.

\section{Sexual contact}

The actions involved in sexual contact involve intercourse and all forms of sexual stimulation performed by the professional and by the patient at the professional's direction. They occur in and outside of the consulting room, in private and National Health Service (NHS) settings. Patients almost never describe a feeling of mutuality or emotional or physical satisfaction: typically they describe 
brief, unsatisfactory sexual encounters. Several factors appear to be important in increasing the experience of harm. Most striking is sexual exploitation that commences with the patient's disclosure of previous sexual abuse; this is so frequently reported that the association cannot be ignored. The use of aspects of previous sexual abuse in the sexual encounter is also sometimes reported. The breach of trust in such situations is particularly stark. The absence of any emotional connection increases the experience of harm because patients feel objectified. Patients who participate because they have experienced an idealising transference (Hook 2018) often feel deceived and confused because their experience of the therapist is the antithesis of the soulmate they anticipated. Other factors that compound the harm are therapists expecting a fee for the session in which sexual contact occurred and therapists resuming a 'therapeutic stance' after the sexual episode. Patients report that both actions increase their feelings of confusion and humiliation.

\section{Seductive or sexualized behaviour}

Sexual boundary violations that do not involve exposure of or contact with sexual organs most often involve seductive behaviours designed to arouse the patient's sexual interest. These include prolonged eye contact, obvious visual attention to the patient's body, and comments on the patient's appearance and attractiveness. Patients often mention the subtle nature of such comments and how this creates confusion about the therapist's intention; they worry that they may have misinterpreted such behaviours. Although some seductive behaviours are part of the 'slippery slope' into sexual contact described by Gabbard \& Lester (1995), patients report instances in which their sexual interest has been aroused to gratify the therapist's ego. Instances involve the patient tentatively responding to sexual advances, only to be rejected. The therapist will often take the moral high ground, but then resume the same behaviour; this 'pull and push' humiliates, confuses and disempowers. This kind of exploitation can be particularly difficult for the patient to articulate and report. Another variety of sexual exploitation involves intrusive sexual discourse such as questioning that does not respect the patient's wish for privacy, the therapist giving unwanted personal sexual information, and the use of lewd language and jokes. Patients report professionals making judgements, both positive and negative, about all aspects of sexual practices and preferences, as if their opinion were a benchmark of normality or desirability. They also report intrusive sexualised gestures, appearance and posture, for example male therapists sitting with legs wide apart, female therapists wearing exposing clothes, and hand gestures symbolising intercourse.

\section{Relationships starting in the consulting room}

Professionals often cite examples of long-term relationships and marriages that result from sexual relationships that began in the consulting room. Generally, this appears to be an attempt to minimise the harm of sexual boundary violations. How we understand such relationships is an important consideration and an area worthy of research. Obvious difficulties present themselves. Such couples are not going to present for treatment. Would they be willing and able to assess their own motivations? How would we assess necessary shifts in hierarchical dynamics? Allowing for the possibility that the disparity in the power relationship will resolve and the love felt is mutual and genuine, we believe that, for the majority, the risks involved (e.g. of unresolved transference dynamics) are sufficiently great to warrant upholding the current position, i.e. that "pursuing a relationship with a former patient is more likely to be (or be seen to be) an abuse of your position if you are a psychiatrist or a paediatrician' (General Medical Council 2013: para. 12). The GMC does not proscribe relationships with former patients altogether, but its advice is clearly that considerable caution should be exercised.

\section{Prevalence of sexual boundary violations}

As with childhood sexual abuse, prevalence is difficult to measure accurately. Figures need to be treated cautiously. Several studies, mostly from surveys of professionals, have reported on prevalence of sexual boundary violations perpetrated by professional workers in psychiatry, psychology, social work and psychotherapy. As mentioned earlier, most of these studies are from North America and are now quite old. Pooled data from these studies (Pope 1994: p. 16) indicates that $4.4 \%$ of the professionals surveyed admitted to having perpetrated a sexual boundary violation. There is a striking gender imbalance: overall, about $7 \%$ of male professionals and $1.5 \%$ of females reported such violations.

One British survey of 1000 psychologists by Garrett (1992) found that $3.5 \%$ of the 581 who responded admitted to sexual boundary violation. However, $22.7 \%$ had treated patients who had been sexually involved with previous therapists and cited 'psychiatrists, private sector psychotherapists, nurses and social workers' as the most commonly involved professions. 


\section{False allegations}

There is justifiable concern about false allegations. We live in a 'complaints' society, with fraudulent claims frequently reported in the media. Social media has provided an easy method of spreading rumour and malicious gossip.

The prevalence of false allegations may be even more difficult to measure accurately than the prevalence of actual violations. One American study (Pope 1991) of psychologists using self-report questionnaires estimated that $4 \%$ of 1000 reported allegations were false.

False allegations have an impact on genuine victims of sexual abuse by professionals. We have worked with many people who report that once they summon the courage to complain, judgements are frequently made about their motivation and they are not believed. False allegations also have an impact on the professionals involved - some suffer life-changing trauma as a result of false accusations, as evidenced by occasional and alarming accounts in the media.

In our experience, false allegations arise from false memories, delusions and malicious reporting. These categories overlap and may be more complex than they appear, particularly in the case of delusions. We are familiar with accounts that have both improbable aspects and clear evidence of boundary violations. Defence lawyers are adept at using improbable content to discredit the whole complaint, resulting in cases being dismissed despite evidence of unacceptable practice. This seems to occur because panels have difficulty in holding the possibility that someone who has suffered a sexual boundary violation may also be predisposed to delusional thinking. Patients with delusions will be just as susceptible to sexual boundary violations as any others. Research carried out by the Crown Prosecution Service demonstrated how difficult it is to prosecute crimes perpetrated against people with mental health problems and intellectual disabilities. Of 45 cases, 32 resulted in 'no prosecution', having failed either the evidential or public interest stages. Of the remaining 13, all were subsequently dropped (Lee 2008).

\section{Harmful effects of sexual boundary violations}

In addition to the negative effects that sexual exploitation has on a person in any sphere of life, sexual boundary violations involving patients result in additional harm due to difficulties in trusting other professionals and accessing treatment. Sexual boundary violations are not always viewed (by the patient and others) as exploitation, because the effects of the power differential and factors such as adverse idealising transference (Hook 2018) are insufficiently recognised. Patients frequently feel a degree of complicity and lose trust in their own judgement. Partners, friends, family and even other professionals may view sexual boundary violations as a romantic affair rather than exploitation, leaving the person without support. Consequences include self-blame, low selfesteem, depression, anxiety and isolation (Box 1). Symptoms of post-traumatic stress disorder are common, with labile mood and flashbacks (Hook 2018). Conflicting emotions are common, where the patient can identify positive aspects of the therapy. There may be a yearning to be with the therapist despite feelings of anger and hate. It can be difficult for patients to process these conflicts and they often believe that they are having a 'breakdown'. In a study of 958 patients who had been sexually involved with a therapist, Pope $\&$ Vetter (1991) found that $11 \%$ required hospital admission, $14 \%$ had attempted suicide and 1\% had died by suicide.

Perhaps the most striking aspect of the harm caused to patients who have experienced sexual boundary violations is the time taken for recovery. This will be influenced considerably by the way the violation was dealt with if it was reported. The harm may last for many years, with limited recovery. In Pope \& Vetter's study only 17\% recovered fully. In our experience, patients who have access to further treatment and have experienced some form of redress have an improved incidence of recovery.

\section{Post-termination relationships}

A question frequently asked is 'How long after therapy or treatment is it OK to have a relationship?' There is no clear answer to this question. Therapists may terminate therapy in order to pursue a relationship, believing that it is only during therapy
B0X 1 Ten of the most common patient reac- tions associated with therapist-patient sex

Ambivalence
Cognitive dysfunction
Emotional lability
Emptiness and isolation
Impaired ability to trust
Guilt
Increased suicide risk
Role reversal and boundary confusion
Sexual confusion
Suppressed anger

(Pope 1991) 
that sexual relationships are proscribed. Perhaps looking at it from a different perspective - 'Why would a therapist want to have a relationship with a patient?' - helps to elucidate some of the problems with this position. It immediately becomes obvious that the answer to this question is complex and involves conscious and unconscious motivations. The primary principle for all therapeutic contracts is concern for the patient and abstinence from actions that pursue the professional's personal gratification in favour of 'thinking about' with the patient and acting on behalf of the patient. The relationship is one of unequal power. Many psychotherapeutic traditions contend that dynamics of failed dependency are usually paramount in therapy. It is difficult to imagine how this type of relationship can be changed to one of an equal and respectful partnership.

It is generally postulated that in therapy, unconsciously, the therapy relationship is formed around the failures of pre-adult developmental experiences. The therapist is placed in and assumes parental, filial and authority roles. These are imbued with incestuous fears and desires. The practical principle at work in relation to these transferences is that "no matter what I (the professional) and you (the patient) think and feel, I will remain in my seat and you in yours and I will not act on such feelings'. Once the possibility arises that this is not so, then therapeutic work becomes impossible. One patient described how effective therapy ended months before the sexual relationship started. These factors are present in all contracts between professionals and patients, even where unconscious experiences are not the focus of the contract. They may be a source of intense disruption to the task.

\section{Trainer-trainee/educator-student sexual relationships}

This is an aspect of sexual relationships occurring in the context of professional responsibility that has received almost no attention. Peltz \& Gabbard (2001) state that analysands of analysts who are perpetrators of sexual boundary violations, even when the analysand has not been the victim, are more likely to commit such violations with their own patients. If this is so, it represents a significant long-term potential for harm to patients, is likely to make exploration of the entire problem within the profession more difficult, and perpetuates unhealthy attitudes and behaviours within professional trainings.

Pope et al (1979) carried out a questionnaire survey of psychologists asking about sexual contact between students and staff - educators and supervisors. Results showed that $9.4 \%$ of respondents had had sexual relationships with staff as graduate students and 13\% had had sexual relationships with students as staff. The predominant pattern was for older, higher status men to engage in sexual relationships with younger, subordinate women for whom they had professional responsibility. Only a minority, even of those who had engaged in sexual relationships as either student or staff, thought such relationships were beneficial.

These findings should alarm us, as they raise the possibility of contamination of the task of training in several ways. It seems likely that students who engage in sexual relationships with professional staff will be treated differently from other students. At the very least, the professionals involved will not be able to maintain an objective appraisal of the students' progress and abilities. Worse is the possibility of outright fraud, in turning a blind eye to the students' failings and giving them preferential treatment or where ambivalence about the relationship exists or there has been rejection or disappointment marking the student down. The overall effect will be to undermine professional values and ethical standards, which may lead to a range of boundary disturbances within the professional organisation and in therapeutic practice.

Pope et al's study found an increasing prevalence of sexual contacts, with 1 in 4 more recent female graduates stating sexual involvement with professional staff. Further research is needed to see whether this trend has continued during the intervening 40 years. They raise several pertinent questions:

- Does sexual contact between psychology students and their educators promote, inhibit or have no effect on the task of training new professionals?

- Is it the case, as the findings of their survey suggest, that students who sleep with their teachers tend themselves, once they become teachers, to engage in sex with their students?

- Do students who are sexually active with their educators tend themselves, once they become therapists, to seduce their patients?

- How does engaging or refusing to engage in sexual contact with their educators affect the personal lives and future careers of psychology trainees?'

They conclude: 'Here the profession must overcome a longstanding failure to acknowledge the area and seek information' (Pope 1979).

\section{Assessment of a victim of professional abuse}

In our experience, patients who present for assessment following abuse by a professional may 
display an increased level of suspicion, hostility and lack of trust towards the assessor. It is important that this is seen in the context of the patient's experience and not a sign of underlying psychopathology. This does not always happen. We have encountered professionals who diagnose borderline personality disorder on the basis of such a presentation and history of professional abuse. Some professionals regard the patient's lack of trust as a contraindication to therapy, instead of viewing it as an adaptive response. Professionals also frequently misdiagnose erotomania (de Clérambault's syndrome) if the patient reports seductive behaviour by another professional. In our experience, this syndrome is extremely rare in this group. Other frequent contraindications cited are uncompleted complaints processes or civil action, and the requirement for an arbitrary gap between therapies. All are unhelpful and do not constitute legitimate contraindications to therapy. The reverse is often the case: patients engaged in complaints processes and/or civil action are likely to have an enhanced need for therapy. The notion of requiring a gap between therapies has no evidential basis and should not apply to a patient who has had an abusive experience of therapy.

Genuine contraindications to therapy are important because harm from a subsequent therapy will compound the previous harm. Most people who seek treatment following professional abuse have experienced an idealising transference in the previous therapy or treatment, and so contraindications centre in particular on whether the patient remains susceptible to developing this type of transference, particularly a transference psychosis. Identifying such patients is not easy. We have found that such patients are often keen to begin therapy and that patients who make a point of comparing the assessor in a favourable way to previous therapists frequently have psychopathology that does not respond well to therapy. These patients typically behave as if they can engage in a therapeutic process until the assessment has been completed and then quickly become disillusioned or envious of the new therapist. They may also try to push the therapist into the behaviours exhibited by the abusive therapist and feel rejected if the therapist does not behave inappropriately. These patients constitute a small proportion of those who have experienced a sexual boundary violation, but it is important to identify them.

At assessment we look for evidence that the patient:

- is not primarily seeking therapy

- is realistic about what therapy can offer

- is motivated to understand and take responsibility for their own behaviour.
It is clear from our experience that unhelpful idealising transferences are gender specific in many, if not most, people, i.e. patients are more likely to develop an idealising transference with another therapist of the same gender as the previous, abusive therapist. This is important information in reducing the risk of adverse idealising transference, as patients often have a strong preference for seeing a therapist of the same gender as their previous therapist and if they do, they are more likely to develop idealisation. It requires discussion at assessment and is a factor in the choice of therapist.

\section{Finding a therapist for a victim of professional abuse}

Patients who have experienced professional abuse often find it difficult to find another therapist. Some therapists would rather not engage with the unpleasant fact that members of the profession can act in an abusive manner. The easy solution is to discredit the patient by disbelieving or pathologising them, thereby compounding the harm. It is essential that the patient find a therapist who is able to work in a non-defensive way, is knowledgeable about professional abuse (or willing to learn) and regards sexual boundary violations as abuse and not a 'cocreation'. Many patients report unhelpful interpretations of this kind.

Although the therapist needs to be empathic and work alongside the patient, it is important that professional boundaries are maintained. This does not mean setting rigid boundaries, but rather appreciating that reliable boundaries help the patient to feel safe. If it is in the patient's interests to extend a boundary, it is essential to convey that this is normal practice and give the reasoning, so the patient understands that this is an extension and not a breach. It is also important for the patient to feel in control of the conversation and free to discuss the abuse as they would any other trauma. Patients frequently report that therapists become irritated by the patient's need to continue to focus on the abuse - some appear to regard this as a defensive manoeuvre and encourage the patient to 'move on' prematurely.

Common factors that are helpfully addressed in treating people who have experienced professional abuse are:

- dealing with the patient's confusion over any good things about the abusive professional and encouraging them to see the professional as having a range of attributes - the good can exist along with the bad and does not diminish it

- encouraging them to accept their own emotions about the professional and normalising their feelings, which can range from love to hate within a few hours 
- tackling any tendency to remain entwined with the professional and linking this with taking back control and power: this means discouraging ruminations that are not linked to problemsolving and discouraging activities that keep them connected, such as following the professional on the internet

- encouraging the patient to seek redress and not revenge.

\section{Supporting a victim of professional abuse when making a complaint}

Patients need different levels of support when making a complaint and although the general practitioner, psychiatrist or therapist may play their part, many patients also need practical support in writing and presenting a complaint and attending complaints hearings. Many patients report dissatisfaction with the advocacy services offered to NHS patients who make a complaint about sexual abuse, in particular that advocates are not knowledgeable about sexual boundary violations. It is often difficult for patients to find appropriate support.

\section{Risk factors in perpetrators}

Research in the USA (Schoener 1989; Gabbard 2002; Celenza 2007) demonstrates the range of typologies and dynamic factors implicated in psychotherapists who commit sexual boundary violations. Box 2 summarises their findings. Another US study, of physicians (MacDonald 2014), supports the potential link between childhood adversity and boundary difficulties, partly mediated by insecure attachment and early maladaptive beliefs. It reports elevated levels of entitlement (i.e. beliefs related to being special and superior, controlling others and having difficulty in reciprocal relationships), emotional inhibition (i.e. excessive inhibition of spontaneous actions, feelings or communication to avoid disapproval or shame), self-sacrifice and unrelentingly high standards (congruent with compulsive personality traits commonly observed in physicians). This demonstration of overlapping features between psychotherapists and physicians in the USA makes it reasonable to make use of these typologies in assessing healthcare professionals in the UK, where no similar systematic studies have been undertaken.

Typologies on their own may have limited value and other factors, such as universal (e.g. Oedipal) and individual fantasies (e.g. rescue fantasy), intensity of contact and current circumstances, remain to be evaluated.

Common factors that, in our experience, confirm the findings in the literature include the presence of dysfunctional personality traits and personality disorder, dysfunctional relationship systems, and cognitive distortions (e.g. entitlement).

The relevance of these typologies is twofold, as they allow predictions to be made about:

- the risk of repeated boundary violating behaviours

- the potential for remediation/rehabilitation.

\section{Clinical vignette}

A male general practitioner in his late 50s developed a sexual relationship with a female patient who presented with depressive illness and family difficulties similar to his own. He was married, with significant marital conflict and a teenage child with mental health problems. He was well-respected by patients and colleagues. There had been no previous concerns about his conduct. He was anxious about retirement, as he had few interests and no confiding relationships. His family history included a neglectful, critical mother and a benign but emotionally unavailable father.

The relationship began with sharing his personal situation with the patient. He increased the frequency of her appointments beyond what was medically necessary, in order to talk. The relationship progressed to meetings outside the surgery. He felt conflicted from the start and tried to end the relationship on several occasions. When he finally did so the patient complained.

At assessment he was found to have depressive, anxious-avoidant and compulsive personality traits on the Inventory of Interpersonal Problems (IIP).

BOX 2 Typologies and dynamic factors characteristic of professionals who commit sexual boundary violations

\begin{tabular}{|c|c|c|}
\hline Schoener \& Gonsiorek (1989) & Celenza (1998) & Gabbard (2016) \\
\hline Uninformed/naive & Long-standing and unresolved problems with self-esteem & Psychotic disorders \\
\hline Healthy or mildly neurotic & Sexualisation of pregenital needs & Predatory psychopathy and paraphilias \\
\hline Severely neurotic and/or socially isolated & Restricted awareness of fantasy & Lovesickness \\
\hline Impulsive character disorders & Covert and sanctioned boundary transgressions by a parental figure & Masochistic surrender \\
\hline Sociopathic or narcissistic character & Unresolved anger towards authority figures & \\
\hline disorders & Intolerance of negative transference & \\
\hline Psychotic or borderline personalities & Defensive transformation of countertransference hate into counter- & \\
\hline Bipolar disorders & transference love & \\
\hline
\end{tabular}


The Medical Practitioners Tribunal Service (MPTS) suspended him from practice for 1 year. The assessor recommended individual and couple therapy, with a return to work to include a number of supportive and supervisory actions, including joining a Balint group and engaging a mentor and clinical supervisor. $\mathrm{He}$ was successfully rehabilitated into practice, with reduced hours and attention to developing appropriate social activities and relationships.

\section{Remediability and rehabilitation of perpetrators}

Gutheil \& Brodsky (2008) have made assessments of remediability - effectively, safe return to practice based on the Schoener \& Gonsiorek categories listed in Box 2. Their conclusions are summarised in Table 1. Here too, more research is needed into what may constitute effective programmes and outcomes of intervention.

The typologies used to describe perpetrators are partially descriptive and partially use diagnostic categories. Although each perpetrator is unique and not every case can be covered by a particular typology, it is possible to place each broadly within one or more categories which, alongside a comprehensive clinical assessment, allows predictions on risk and remediation to be made.

What happens to perpetrators is a matter of considerable debate. Patients, understandably perhaps, mostly feel that they should not be allowed to practise again. Health regulators perceive their primary role to be protection of the public. In the UK, sanctions available for doctors via 'fitness to practise' procedures (MPTS, GMC 2018) include return to work with conditions, suspension and erasure from the professional register. Sexual offences are likely to receive more serious sanctions. Finding therapists who have the experience of working with professional perpetrators is a significant problem.

Therapy organisations have focused on return to therapy, supervision and continued professional development (CPD). However, these are determined from the fact of the violation and are not based on a detailed psychological and psychiatric assessment of the professional. In our experience, risk appears to be measured through the fitness to practise or complaints process by an 'informal' assessment of expression of remorse, acknowledgement of what is often simplistically regarded as sexual motivation and empathy for the victim. Although these factors will form part of an assessment of risk and rehabilitation, they are of limited value on their own.

\section{An assessment model}

Celenza \& Gabbard (2003), among others, describe detailed intensive assessment followed by a carefully constructed rehabilitation programme that includes independent oversight of the process. At the Clinic for Boundaries Studies, we are beginning to gain experience of assessing professionals, currently

TABLE 1 Typologies and rehabilitation potential (remediability) of perpetrators of sexual boundary violations

\begin{tabular}{|c|c|c|}
\hline Type & Description of profile & Remediability \\
\hline Naive & $\begin{array}{l}\text { These individuals usually respond well to appropriate retraining unless their } \\
\text { psychological and interpersonal naivety is characterological rather than } \\
\text { situational }\end{array}$ & Maybe \\
\hline Normal and/or mildly neurotic & Generally, have one victim. These are good prospects for rehabilitation & Yes \\
\hline $\begin{array}{l}\text { Severely neurotic and/or } \\
\text { socially isolated }\end{array}$ & $\begin{array}{l}\text { Tend to be repeat offenders. Therapists in this group vary in their potential for } \\
\text { rehabilitation because of their longstanding intrapsychic and life problems. }\end{array}$ & Maybe \\
\hline Impulse control disorders & $\begin{array}{l}\text { Generally, repeat offenders. Clinical experience indicates that these individuals } \\
\text { cannot be rehabilitated and therefore should be removed from positions where } \\
\text { they can harm others }\end{array}$ & No \\
\hline $\begin{array}{l}\text { Sociopathic or narcissistic } \\
\text { personality disorders }\end{array}$ & $\begin{array}{l}\text { Repeat offenders most often. Their manipulativeness extends to appearing } \\
\text { remorseful when caught and making a show of participation in a rehabilitation } \\
\text { programme. In fact, they are almost always impervious to character change and } \\
\text { should be removed from positions of clinical responsibility }\end{array}$ & No \\
\hline $\begin{array}{l}\text { Psychotic and severe borderline } \\
\text { disorders }\end{array}$ & $\begin{array}{l}\text { The future behaviour of these individuals tends to be unpredictable, and therefore } \\
\text { they are not considered amenable to rehabilitation and reinstatement as clinical } \\
\text { professionals }\end{array}$ & No \\
\hline Sex offenders & $\begin{array}{l}\text { These are paedophiles and other aggressive sex offenders. They commit offences } \\
\text { that would be criminal even outside the context of therapy. Healthcare and } \\
\text { clerical professions offer such a temptation to reoffend that these are generally } \\
\text { not considered appropriate work settings for such individuals }\end{array}$ & No \\
\hline Medically disabled & $\begin{array}{l}\text { Neurological impairments or bipolar mood disorders. The rehabilitation potential of } \\
\text { medically impaired therapists depends on the treatability of their medical } \\
\text { condition }\end{array}$ & Maybe \\
\hline Masochistic/self-defeating & $\begin{array}{l}\text { Their deeply dysfunctional personality structure makes their prognosis for } \\
\text { rehabilitation guarded }\end{array}$ & Probably no \\
\hline
\end{tabular}

Source: Gutheil \& Brodsky (2008: pp. 223-5). 
doctors (mostly self-referrals during MPTS proceedings), using a model of assessment adapted from experience in the USA. The individual's consent is sought at the outset for the whole process. We conduct: an in-depth psychiatric and psychodynamic interview; third-party interviews with spouse, family, close friends and work colleagues (we may interview the victim(s) if and when appropriate and possible); psychological tests, including personality assessment (International Personality Disorder Examination (IPDE); Millon Clinical Multiaxial Inventory-111 (MCMI-111)), relational systems (Inventory of Interpersonal Problems (IIP)), defence patterns (Defence Style Questionnaire (DSQ)) and mental health (CORE Outcome Measure (CORE-OM)). The aims of the assessment are to provide a formulation combining: personal and situational factors that have led to the boundary violation; an evaluation of risk factors operating at the time of the offence, those that remain in operation and those that may be amenable to change; assessment of risk of repetition of boundary violating behaviour; and assessment of the probability of successful rehabilitation, with recommended actions, prognosis and timescale.

We believe that such an assessment would enhance regulators' primary responsibility of public protection by providing them with a formulation on which to base appropriate sanction and affording them the opportunity to return to work professionals who, until the time of the offence, have often provided a good standard of care and have considerable expertise and experience.

\section{How can we make professional practice less harmful?}

Individual practitioners at all stages of professional development need to be aware that, under adverse circumstances, they can become vulnerable to meeting their own needs through inappropriate relationships with patients. Should they feel at risk it is essential that they seek advice and support from e.g. a trusted colleague or the College's Psychiatrists' Support Service.

Psychotherapy, psychiatry and other professions might consider action in the following areas in order to increase their knowledge about sexual boundary violations, reduce the risks of harm by professionals,improve the outcomes for patients and professionals when harm has occurred, and restore the confidence of the public.

\section{Teaching}

Psychotherapy and mental health professions might teach practitioners about the potentially harmful effects of psychotherapy, what is known about how these arise and what can be done to minimise the risk of harm. All health professions, not just psychotherapy and mental health, might teach specifically about sexual boundary violations, how they arise and what can be done to minimise the risk of violations (Swiggart 2002). Such training would also be beneficial in other professions that work with relationships of power imbalance and vulnerable people, such as the police, teachers and clergy.

\section{$C P D$}

In CPD, ethical issues and professional responsibilities regarding harm, sexual attraction and sexual boundary violations might be made mandatory areas of study for continued registration and for supervisors.

\section{Reflective practice}

Psychotherapy might develop a self-critical attitude to the question of harm caused by therapies. This includes listening to patients' complaints with respect and openness, a willingness to accept error in practice and the limitations of theory, and acknowledgement of failures at individual and systemic levels.

\section{Research}

There should be continued research into the types, effects and causes of harm in psychotherapy. Parry et al (2016) and Scott \& Young (2016) argue for a coherent framework for studying unwanted events, adverse reactions, professional malpractice and deterioration of illness, clearer definitions of harm and reporting of harmful events in clinical trials and audits. Research is also needed to establish what actions effectively reduce the risks of harm and what actions can be taken to repair instances of harm.

\section{Codes of ethics}

Ethical codes of psychotherapy might adequately reflect the patient's vulnerable position in the patient-therapist relationship and make clear the professional's responsibility to protect patients from harm. This would include clear mechanisms of reporting suspected harm. Ethical codes might also cover relationships between teachers and trainees.

\section{Interagency cooperation}

Organisations involved in investigating and prosecuting sexual boundary violations need to be able to communicate effectively with each other in sharing necessary information, i.e. rules regarding confidentiality need to be clarified when patients have been subject to abuse or are at risk of abuse. 
MCO answers

1 b 2 d 3 c 4 c 5 b

\section{Sanctions}

Healthcare regulators together with healthcare professions need to consider the range of appropriate sanctions based on assessment of risk and potential for rehabilitation of perpetrators. This will include education of practitioner health insurers, psychiatrists who assess practitioners at hearings, assessing panels and legal representatives.

\section{Patient education}

Patients entering psychotherapy should be given information about its potential harmful effects, how to raise concerns with their therapists and how to make a complaint if they remain dissatisfied. Patients should also be made aware of actions that are never acceptable in psychotherapy or professional practice in general.

\section{Reporting concerns and problems}

Where personal therapy is a key component of psychotherapy training, providers might consider therapists' responsibilities in reporting concerns when they suspect that a colleague's patients are at risk of harm. For patients, there might be a system similar to the yellow card system, requiring therapists to allows patients to report problems in psychotherapy - Nutt \& Sharp (2008) suggest that this might be referred to as the 'pink card' system.

\section{The future and the role of the Royal College of Psychiatrists}

Some of these recommendations will prove controversial and require careful consideration. We suggest that the process of thinking through the implications of these recommendations will itself be beneficial in leading to a change of attitude towards harm and in improving the quality of medical, psychiatric and psychotherapeutic practice.

Psychiatrists are integral to the provision of mental healthcare. In providing treatment and therapies across the whole range of specialties and patient age groups they have a unique position from which to positively influence patient safety and address reduction in harm.

A number of the Royal College of Psychiatrists' publications (e.g Sarkar 2004; Subotsky 2010; Royal College of Psychiatrists 2009, 2013) and its CPD module on boundary violations and sexual exploitation (Margerison 2016) could be built on in order for the College to take a leading role in supporting research and in teaching, training and supervision related to boundary violations and harm in the psychiatric profession and across mental healthcare. College journals could commission more articles on the subject and encourage local and national conferences to include related topics in their programmes. These might consider, for example, the inclusion of boundary ethics in the curriculum, specific competencies to be demonstrated by senior trainees, and CPD on harm across the professional life cycle as part of selfreflective practice.

\section{Conclusions}

Therapy-related harm in general, and sexual boundary violations in particular, are largely an outcome of the mismanagement of processes that are common to working with suffering and vulnerable people in a context of power-imbalanced relationships. Mismanagement has its roots in a persistent failure of the professions to acknowledge harm; inadequate training about harm and boundary issues; treating patients beyond one's expertise and experience; and personal factors in the professional. It therefore makes sense to treat the problems we have described not as unusual separate issues, but as integral to the process of therapy and treatment.

Power imbalance in professional-patient relationships cannot be avoided and attempts at making the power relationship more equal (such as self-disclosure) are likely to have harmful consequences. It is necessary to keep the imbalance constantly in mind. It can be used as a parameter in reflective processes for thinking about the quality of the therapeutic relationship. We can think about it in terms of our attitude to patients, the type of language we use and the style of communication we adopt. All healthcare professionals should be aware of the potential to harm their patients and should continually guard against it.

\section{References}

Celenza A (1998) Precursors to therapist misconduct: preliminary findings. Psychoanalytic Psychology, 15: 378-95.

Celenza A, Gabbard GO (2003) Analysts who commit boundary violations: a lost cause? Journal of the American Psychoanalytic Association, 51: 617-36.

Celenza A (2007) Sexual Boundary Violations: Therapeutic, Supervisory, and Academic Contexts. Jason Aronson.

Council for Healthcare Regulatory Excellence (2008) Learning about Sexual Boundaries between Healthcare Professionals and Patients: A Report on Education and Training. CHRE.

Gabbard GO, Lester EP (1995) Boundaries and Boundary Violations in Psychoanalysis. Basic Books.

Gabbard GO (2016) Boundaries and Boundary Violations in Psychoanalysis (2nd edn). American Psychiatric Association Publishing.

Garrett T, Davis JD (1998) The prevalence of sexual contact between British clinical psychologists and their patients. Clinical Psychology and Psychotherapy, 5: 253-63.

General Medical Council (2013) Maintaining a Professional Boundary Between You and Your Patient. GMC.

Gutheil TG, Brodsky A (2008) Preventing Boundary Violations in Clinical Practice. Guilford Press.

Hook J, Devereux D (2018) Boundary violations in therapy: the patient's experience of harm. BJPsych Advances, 24: 366-373. 
Lee V, Charles C (2008) Research into CPS Decision-Making in Cases Involving Victims and Key Witnesses with Mental Health Problems and/or Learning Disabilities. Crown Prosecution Service.

MacDonald K, Sciolla A, Folsom D, et al (2014) Individual risk factors for physician boundary violations: the role of attachment style, childhood trauma and maladaptive beliefs. General Hospital Psychiatry, 37: 489-96.

Margerison N, Bewley S (2016) Boundary Violations and Sexual Exploitation: Recognition, Avoidance and Management (CPD Online module). Royal College of Psychiatrists.

MPTS, GMC Sanctions Guidance (2018) (www.gmc-uk.org; www.mptsuk.org).

Nutt D, Sharp M (2008) Uncritical positive regard? Issues in the efficacy and safety of psychotherapy. Journal of Psychopharmacology, 22: $3-6$

Parry G, Crawford M, Duggan C (2016) latrogenic harm from psychological therapies - time to move on. British Journal of Psychiatry, 208: 210-2.

Peltz ML, Gabbard GO (2001) Speaking the unspeakable: institutional reactions to boundary violations by training analysts. Journal of the American Psychoanalytic Association, 49: 659-73.

Pope K, Levenson H, Schover L (1979) Sexual intimacy in psychology training: results and implications of a national survey. American Psychologist, 34: $682-9$
Pope KS, Vetter VA (1991) Prior therapist-patient sexual involvement among patients seen by psychologists. Psychotherapy, 28: 429-38.

Pope KS (1994) Sexual Involvement with Therapists: Patient Assessment, Subsequent Therapy, Forensics. American Psychological Association.

Royal College of Psychiatrists (2009) Good Psychiatric Practice (3rd edn) (College Report CR154). Royal College of Psychiatrists.

Royal College of Psychiatrists (2013) Vulnerable Patients, Safe Doctors: Good Practice in our Clinical Relationships (2nd edn) (College Report CR180). Royal College of Psychiatrists.

Sarkar SP (2004) Boundary violation and sexual exploitation in psychiatry and psychotherapy: a review. Advances in Psychiatric Treatment, 10: 312-20.

Schoener G, Gonsiorek J (1989) Assessment and development of rehabilitation plans for the therapist. In Psychotherapists' Sexual Involvement with Clients: Intervention and Prevention (eds G Schoener, J Milgrom, J Gonsiorek, et al). Walk-in Counseling Center.

Scott J, Young AH (2016) Psychotherapies should be assessed for both benefit and harm. British Journal of Psychiatry, 208: 208-9.

Subotsky F, Bewley S, Crowe M (eds) (2010) Abuse of the Doctor-Patient Relationship. RCPsych Publications.

Swiggart W, Starr K, Finlayson R, et al (2002) Sexual boundaries and physicians: overview and educational approach to the problem. Sexual Addiction \& Compulsivity, 9: 139-48.

\section{MCOs}

1 Sexual boundary violations:

a always include physical acts

$\mathrm{b}$ are an abuse of power

c are mostly initiated by the patient

$\mathrm{d}$ are best understood as a love affair

e only take place in the consulting room.

2 Effects of a sexual boundary violation on the patient:

a include sexual gratification

b include enhanced well-being

c include improved marital relationships

d include impaired ability to trust

e are time-limited.
3 Sex between professional staff (educators and supervisors) and trainees:

a is always consensual

b has no ill-effects

c may lead trainees to commit sexual boundary violations with patients

d occurs most commonly among female staff

$\mathrm{e}$ is rare.

4 Patients who have suffered a sexual boundary violation:

a should not be offered further therapy

b should only be seen with a chaperone

c are more likely to self-harm

d suffer no long-term ill-effects

e need to see a therapist of the same gender as the violator.
5 Perpetrators of sexual boundary violations: a are most commonly predatory

b have long-standing problems with self-esteem

c should always be removed from the professional register

d do not require psychological evaluation

e have a personality disorder. 